\title{
Use of the van Hiele Theory in Investigating Teaching Strategies used by College of Education Geometry Tutors
}

\author{
Robert Benjamin Armah ${ }^{1^{*}}$, Philip Siaw Kissi ${ }^{2}$ \\ ${ }^{1}$ Department of Mathematics Education, University of Education, Winneba, GHANA \\ ${ }^{2}$ Management Information Systems, School of Applied Sciences, Cyprus International University, Nicosia, Northern Cyprus, \\ Mersin 10, TURKEY
}

Received 18 October 2017 • Revised 1 November 2018 • Accepted 15 December 2018

\begin{abstract}
The main purpose of this study is to explore the extent to which 11 selected mathematics tutors facilitate the teaching and learning of geometry at the van Hiele Levels 1, 2, 3 and 4 at the college of education level in Ghana. The van Hiele theory of geometric thinking was used to explore the type of teaching strategies employed by the mathematics tutors. The theory served as a guideline from which classroom observation protocol was developed. Results indicated that the tutors exhibit a good conceptual understanding in facilitating the teaching and learning of geometry that is consistent with van Hiele Levels 1 and 2. However, much of the geometry teaching and learning strategies of the mathematics tutors were not structured in a way that support the development of geometric thinking as described in van Hiele Levels 3 and 4. Implications for the involvement of college mathematics tutors in utilizing the van Hiele framework were discussed.
\end{abstract}

Keywords: teaching strategies, van Hiele Levels, pre-service teachers, college tutors

\section{INTRODUCTION}

The mathematics Curriculum in Ghana (Ministry of Education, Science and Sports (MOESS), 2007) reverberates the belief of researchers (Al-ebous, 2016; Alex \& Mammen, 2016; Furner \& Marinas, 2011; Jones, 2002) that geometry is an essential subject which deserves significant attention in the teaching of mathematics. This is because geometry considered as a tool for understanding and interacting with the natural world is perhaps the most intuitive, concrete and reality-linked part of mathematics (Güven \& Kosa, 2008). It is in the language of geometry that the physical and also imagined spatial environments are conceptualized and analyzed, thus, helping students to develop the skill of critical thinking, deductive reasoning and problem-solving (Alex \& Mammen, 2012).

In contemporary mathematics and technology, relevant concepts such as symmetry are most simply introduced in a geometric context. Moreover, real life activities such as designing an electronic circuit board, a building, a dress, an airport, a bookshelf, or a newspaper page, necessitate an understanding of geometric principles (Yegambaram \& Naidoo, 2009). As a result of the importance of geometry in both education and real life, many countries and educational jurisdictions are concerned about how teachers teach and how learners learn various aspects of the subject.

In Ghana, geometry forms a substantial amount of the college of education mathematics curriculum as it is put into two major aspects; content aspect, studied in the first year and methodology aspect, which is studied in the second year (Institute of Education, 2005). Geometry at the primary school level is treated as shape and space, occupying approximately $17 \%$ of the 6 major content areas covered in the mathematics teaching syllabus. The main aim of teaching shape and space is to enable learners "organize and use spatial relationships in two or three dimensions, particularly in solving problems" (MOESS, 2007, p. ii) and also to help them possess a better understanding of other concept areas in mathematics. Thus, the teaching of geometry at the college of education level should be done in ways that promote geometric thinking; so that pre-service teachers can in turn prepare their basic school pupils to effectively master the subject.

(c) 2019 by the authors; licensee Modestum Ltd., UK. This article is an open access article distributed under the terms and conditions of the Creative Commons Attribution License (http://creativecommons.org/licenses/by/4.0/). \armahrb@gmail.com (*Correspondence) $\bigotimes$ philip.asakomah@yahoo.com 


\section{Contribution of this paper to the literature}

- In Ghana, colleges of education are responsible for training basic school teachers. It is recognized that Ghanaian basic school learners have great difficulties in geometry.

- This study investigated the teaching strategies used by college of education geometry tutors in Ghana using the van Hiele theory as a lens.

- The study developed an observation schedule that could be used to investigate the tutors' teaching strategies. The results from the study showed that the tutors have good conceptual understanding in facilitating the teaching and learning of geometry that is consistent with van Hiele Levels 1 and 2 but not at levels 3 and 4 .

Basic school geometry teaching has conventionally focused on the categorization of shapes (Baffoe \& Mereku, 2010). As a result of living in a three-dimensional world, learners enter school with a significant amount of intuitive geometric experience. Yet, most mathematics teachers teach geometric concepts using just textbooks and the chalkboards (De Villiers, 2012; Khalid \& Azeem, 2012). In most geometry lessons, the main emphasis is put on twodimensional geometry, while three-dimensional geometry rather stays in the background. Ordinary routine calculations dominate geometric activities while spatial-visual skills are frequently and extensively avoided (Christou, Jones, Pitta, Pittalis, Mousoulides \& Boytchev, 2007; Yegambaram \& Naidoo, 2009). Currently, existing evidence indicates that traditional textbook-chalkboard teaching strategies do not provide significant spatial experience (Alex \& Mammen, 2016; Erdogan \& Durmus, 2009).

Geometry learning is problematic to many students, as they fail in developing the appropriate understanding of geometric concepts and in acquiring the geometric problem solving skills. Van Hiele (1986) attributed this to the fact that traditionally, teachers presented the curriculum at a higher level than those of the students. In the view of Alex and Mammen (2012) students' weakness in geometric thinking may be due to teachers' failure to use effective and appropriate teaching methods that will actively engage students and help them use their thinking skills effectively. Shulman (1987) made a distinction between three groups of knowledge that a teacher should hold in order to teach successfully. These are content knowledge, pedagogical content knowledge and curriculum knowledge. Nevertheless, emphasis is heavily placed on pedagogical content knowledge "because it identifies the distinctive bodies of knowledge for teaching" (Shulman, ibid.).

Studies (Armah, Cofie, \& Okpoti, 2017; Gogoe, 2009) suggest that majority of Ghanaian pre-service teachers geometrical knowledge is abysmally low. These studies have therefore suggested the need for educators to adopt model-based teaching strategies that are supportive and involve more hands-on investigations that will actively involve the pre-service teachers. This is buttressed by the Ghanaian mathematics curriculum (MOESS, 2007) when it endorses the use of realia and model-based instructions. The van Hiele model is one of such model-based instructions recommended by many authors in literature for effective geometry instruction (Alex \& Mammen, 2016; Howse \& Howse, 2015; Mostafa, Javad \& Reza, 2017).

Research has shown that, studies on the van Hiele theory and how students learn geometry is an important source to understanding teachers' pedagogical content knowledge on geometry teaching (Erdogan \& Durmus, 2009; Halat, 2008). The van Hiele theory has been suggested to be the best and most well-defined theory for students' levels of thinking in the field of geometry (Alex \& Mammen, 2016; Rizki, Frentika \& Wijaya, 2018). The theory was created to provide and develop geometric understanding. The van Hiele theory categorizes students learning abilities in geometry into five distinct and hierarchical Levels of geometric thinking, and also offers a model of teaching that teachers could apply in order to promote their learners' levels of understanding in geometry. This is because the teacher has to be aware of effective teaching methods that are aimed at raising students' understanding and giving students the opportunity to participate in the process of teaching.

\section{OVERVIEW OF THE VAN HIELE THEORY}

\section{The van Hiele Levels}

The van Hiele theory originally consists of five sequential and hierarchical discrete Levels of geometric thought namely: Visualization, Analysis, Order (Informal Deduction), Deduction, and Rigor (van Hiele, 1986). Each of the five Levels (see Table 1) describes the thinking processes used in geometric contexts. As one progresses from one Level to the next, the object of one's geometric thinking changes. In primary school, students tend to move from level 1 to level 2. For example, at level 1, learners recognize figures by appearance alone "and compare the figures with their prototypes or everyday things ("it looks like a door"), categorize them ("it is / it is not a..."). They use simple language" (Vojkuvkova, 2012, p.72). At level 2, learners start analyzing and naming properties of geometric figures but they do not understand the interrelationship between different types of figures. Then in junior high 
Table 1. van Hiele theory of geometric thought

Level Description Ability of student

\begin{tabular}{cll} 
Level & Description & Ability of student \\
\hline $\mathbf{1}$ & Visual & Describes shapes on the basis of their appearance \\
\hline $\mathbf{2}$ & Analysis & Describes shapes on the basis of their properties \\
\hline $\mathbf{3}$ & Order & $\begin{array}{l}\text { Recognizes the importance of properties and the relationships among them, which assist students in } \\
\text { logically ordering the properties of the shapes }\end{array}$ \\
\hline $\mathbf{4}$ & Deduction & Attains logical reasoning ability and proves theorems deductively \\
\hline $\mathbf{5}$ & Rigor & Establishes and analyzes theorems in different postulation systems \\
\hline Source: & Howse \& Howse, 2015.
\end{tabular}

Table 2. Framework of the van Hiele phases of Teaching

\begin{tabular}{ll}
\hline Phase & Descriptions \\
\hline $\begin{array}{l}\text { Information } \\
\text { Directed } \\
\text { orientation }\end{array}$ & $\begin{array}{l}\text { Teachers guide students to develop vocabulary and concepts for a particular task. The teacher assesses } \\
\text { students interpretation/reasoning and determines how to move forward with future tasks. }\end{array}$ \\
\hline $\begin{array}{l}\text { Explicitation } \\
\text { to gain an understanding of them as well as the connections among them. }\end{array}$ & Students are given the opportunity to verbalize their understanding. The teacher leads the discussion. \\
\hline $\begin{array}{l}\text { Free } \\
\text { Orientation }\end{array}$ & Students are challenged with tasks that are more complex and discover their own ways of completing each task. \\
\hline Integration & Students summarize what they have learned, creating an overview of the concept at hand. \\
\hline
\end{tabular}

school learners move to level 3 where they see the interrelationship between different types of figures. They can create meaningful definitions and give informal arguments to justify their reasoning at this Level. Logical implications and class inclusions, such as squares being a type of rectangle, are understood at this level (Halat, 2008). Learners at level 4 can give deductive geometric proofs. They understand the role of definitions, theorems, axioms and proofs. It is the view of Schwartz (2008) that since senior high school geometry curriculum is built on geometric proofs, this is the level of development that they need to be prior to completion of senior high school. Learners at Level 5 "understand the formal aspects of deduction, such as establishing and comparing mathematical systems" (Mason, 1998, p. 5). Here, learners learn that geometry needs to be understood in the abstract; see the "construction" of geometric systems. The basis of the van Hiele theory is the idea that a student's growth in geometry takes place in terms of distinguishable levels of thinking. In planning geometry lessons, it is important to have these levels in mind (Choi-koh 1999 cited in Howse \& Howse, 2015).

\section{The van Hiele Teaching Phases}

According to van Hiele (1986), cognitive progress in geometry can be accelerated by instruction and that there are five phases in the teaching process that promote students' progress from one van Hiele level to the next in geometry classroom instruction. The van Hiele phases (see Table 2) are Inquiry/information, Directed/guided orientation, Explicitation/explanation, Free orientation, and Integration. The approach used in these five phases provides a structured lesson by giving clear explanations of how the teacher should proceed to guide students through "introductory discussion, straightforward exercises, language development, multi-path solution exercises and topic overview in a sequence" (Pegg, 1995, p.98) as they move from one level to the next. The current study used the van Hiele theory which encompasses the levels of geometric thinking and the phases of instruction. The phases of instruction specifically considers teachers' mode of instruction; the main objective at this point was to explicate the pedagogical patterns of geometry instruction in colleges of education in Ghana using the van Hiele phases as a lens.

\section{RESEARCH ON THE USE OF VAN HIELE THEORY IN INVESTIGATING GEOMETRY TEACHING STRATEGIES}

A review of literature on the van Hiele theory in geometry instruction has revealed a global advocacy for its adoption to improve the way geometry is taught and learnt (Alex \& Mammen, 2016; Howse \& Howse, 2015; Suwito, Yuwono, Parta \& Irawati, 2017). This advocacy for the use of the van Hiele theory has implications for mathematics teacher education since the teacher is the driving force in any instructional process. Teacher training institutions have to provide not only professional knowledge but also instructional design capacities to pre-service/prospective teachers to enable them to implement the van Hiele theory in their teaching (Armah et al, 2017). The aim of this provision is to afford pre-service teachers with what is required to teach with strategies and approaches proved to be effective. 
In examining how geometrical concepts were taught to a group of pre-service teachers, van Putten (2008) employed the van Hiele theory of levels of teaching as the theoretical framework. Findings indicated that most preservice teachers were taught geometry with route learning methods, using textbooks to present theorems and proofs. Moreover, most proof exercises given to the pre-service teachers were not challenging enough to compel pre-service teachers to engage in effective reasoning. As a result, most of the pre-service teachers could not recall geometric concepts which were taught and were also not able to logically apply the concepts.

Similarly, Muyeghu (2008) investigated the extent to which mathematics teachers facilitate the teaching and learning of geometry at the van Hiele levels 1 and 2 at a Grade 10 level in selected schools in Namibia. The van Hiele theory of geometric thinking and the five Kilpatrick components of proficient teaching were used to investigate the type of teaching strategies employed by the mathematics teachers. These components include conceptual understanding, procedural fluency, strategic competence, adaptive reasoning, and productive disposition (Kilpatrick \& Findell, 2001). Findings obtained from the classroom observations and interviews indicated that much of the teaching and learning of Grade 10 geometry teachers in the selected schools are structured in such a way to support the development of geometric thinking as described in the van Hiele theory, particularly at levels 1 and 2. However, the study found evidence indicating that gaps exist with regard to the facilitation of the teaching and learning of geometry in the schools studied.

Ding and Jones (2007) also analyzed the teaching of geometrical proof at (the lower secondary school level) grade 8 in Shanghai, China using the van Hiele theory. The analysis indicated that though the first three of the van Hiele teaching phases were found in the Chinese lessons, the instructional intention of the guided orientation was not exactly the same as that identified by van Hiele. The study suggested that teachers use classroom strategies which attempt to reinforce visual and deductive approaches in order to develop learners' thinking in the transition to deductive geometry instruction.

Using the van Hiele model of geometry instruction as a lens, Atebe (2008) explored geometry instructional practices that possibly contributed to the levels of geometric conceptualization exhibited by a group of high school learners in Nigerian and South African schools. Videotaped lessons were analyzed to determine its conformity with criteria on the checklist of van Hiele phase descriptors developed for the study. Observation findings indicated that instructional processes in the majority of the lessons videotaped did not conform to the van Hiele model of instruction in the geometry classroom. By comparing the van Hiele model of geometry instruction with the observed geometry instructional approaches, Atebe (2008) concludes that the geometry teaching approaches in Nigerian and South African classrooms give learners little opportunity to learn the subject. This according to the researcher resulted in the low levels of geometric conceptualization of the cohorts of learners from these areas.

However, in a similar study explaining why Japanese school learners usually outperformed many of their counterparts from other countries in TIMSS, Stigler and Hiebert (1999) concluded that schools in Japan use teaching methods which offer greater opportunities for learning mathematics. Atebe (2008) suggests that in order to teach geometric concepts well, knowledge, skill and judgement are required. Instruction based on the van Hiele model develops substantial geometrical knowledge and lifelong learning skills (Alex \& Mammen, 2016). Given the findings of these studies, it would seem that learners whose instructional experiences are in line with the van Hiele phases of learning are most likely to exhibit a better understanding of geometric concepts. One of the strengths of using the van Hiele framework is that the advancement of learners from one geometric thinking level to the next depends more on teaching than on the chronological age of the learner. Teacher training institutions should take note of this as they have the sole mandate of preparing pre-service/prospective teachers for pedagogical activities in the classroom.

\section{PROBLEM STATEMENT}

A number of studies have been carried out to investigate pupils understanding in mathematics in Ghana (Anamuah-Mensah \& Mereku, 2005; Anamuah-Mensah, Mereku \& Asabere-Ameyaw, 2008; Baffoe \& Mereku, 2010). These studies have reported nothing but the abysmal performance of pupils especially in the field of geometry. The study by Baffoe and Mereku (2010) specifically sought to find out the stages of the van Hiele levels of understanding Ghanaian students reach in the study of geometry before entering senior high school. Results from the study indicated that the stage of the van Hiele level of understanding reached by most (i.e. over $90 \%$ ) Ghanaian students before entering senior high school is lower than what most students at this stage reach in other countries in the study of geometry.

An empirical study (Armah et al., 2017) corroborated with the above evidence where majority of Ghanaian preservice teachers who took part in that study attained very low levels of van Hiele geometric thinking in a test conducted to assess their geometrical thinking levels. In the study, $75.33 \%$ of pre-service basic school teachers' van Hiele Levels of geometric thinking was below Level 3 (Order). This pointed out to the fact that the pre-service teachers operate at a van Hiele Level that is lower than that expected of their future learners. It is, therefore, 
necessary to look at the kind of training and preparation being given to pre-service teachers in geometry. This is because "the issue of providing quality education to pupils is directly related to the quality of teachers in the system" (Ampiah, 2010, p. 3).

The van Hiele theory has motivated a considerable amount of research in many developed countries (Howse \& Howse, 2015; Ma, Lee, Lin, \& Wu, 2015; Noh \& Abdullah, 2016; Tieng \& Eu, 2014) and this has resulted in changes in their geometry curricula and teachers' instructional approaches. However, in Ghana, the literature suggests that studies on the van Hiele theory are limited. For Ghana to realize significant development there is the need for a resilient education system which can contest in the global world of mathematics. This can materialize if there are good teachers who can continuously advance the teaching strategies in mathematics especially in the geometry classroom. Teachers should, therefore, be trained to pose as facilitators of learning and their instructional approaches should be in agreement with what has been proved to be effective.

\section{PURPOSE OF THE STUDY AND RESEARCH QUESTION}

Geometry is one of the major areas of mathematics where students' performance has been abysmal. Over the years research has shown that many students are having difficulties in learning geometry and making wrong associations in geometry classrooms (Alex \& Mammen, 2012; Armah et al, 2017; Rizki, Frentika \& Wijaya, 2018). It is for these reasons that the researchers found it expedient to explore more rigorously the way geometry is taught and in particular how college of education mathematics tutors facilitate the learning of geometry. In pursuance of this purpose, the following research question was formulated to guide the study: To what extent do college of education mathematics tutors facilitate geometry teaching and learning consistent with the van Hiele Levels of geometric thinking?

\section{METHODOLOGY}

\section{Research Design}

This research is conducted within an interpretive orientation. Theoretically, interpretive paradigm gives researchers the opportunity to see and understand the world through the perceptions and experiences of the participants. Interpretivist researchers, therefore, discover reality through participant's views and experiences (Yanow \& Schwartz-Shea, 2011). The researcher who employs interpretive paradigm uses those experiences collected to build and interpret his understanding from gathered data so as to find the answers for research (Thanh \& Thanh, 2015).

The researchers adopted a case study methodology as it aligns consistently with an interpretive orientation. Willis (2007) emphasized that "interpretivists tend to favour qualitative methods such as case studies and ethnography" (p.90). He argues that qualitative approaches such as case studies give exhaustive accounts that are essential for interpretivists to entirely appreciate circumstances. Following the nature of the interpretive paradigm and case studies, the researchers conducted this study to elaborate and explore the extent to which college of education mathematics tutors facilitate geometry teaching and learning consistent with the van Hiele Levels of geometric thinking.

\section{Participants and Setting}

The study involved eleven college of education mathematics tutors who were purposively selected from four colleges of education in the Ashanti, Central and Greater-Accra regions of Ghana. Two of the tutors had Master of Philosophy degree, seven had Master of Education degree while the other two had Bachelor of Education degree in Mathematics. All the tutors attended the two major teacher training universities in Ghana, University A and B. Two of the tutors had ten years of teaching experience at the college of education level, three had eight years teaching experience while the rest had less than six years of teaching experience. There were one female tutor and ten male tutors. Three of the tutors were between 40 to 45 years, another three were between 36 to 39 years and the rest were between 30 to 35 years. The participants were assured of their right to confidentiality and anonymity and were also informed of their right to withdraw from the study at any stage.

\section{Data Collection}

In this study, data were gathered through classroom observation. The classroom observation schedule was adapted from Muyeghu (2008) based on the van Hiele theory. The schedule was constructed by taking into account the findings of researchers on the knowledge and skills pre-service teachers and tutors need to master and facilitate at the various van Hiele Levels. Muyeghu (2008) considered the role of the teacher at the Visual Level as well as at 
the Analysis Level thus activities at the Visual Level (Level 1) and at the Analysis Level (Level 2) were shown in his schedule. These activities were evaluated against the teacher's practice to determine the teaching strategies that selected teachers used to facilitate the development of geometric thinking at the van Hiele Levels 1 and 2 (Muyeghu, 2008). However, for the purpose of this study, the researchers adapted the observation schedule by extending the Levels to include Levels 3, and 4. The schedule assessed the teaching skills of the tutors on a three-point scale. They are weak, moderate and strong. There was an additional column for any comment that the researchers wished to make.

Each tutor was observed twice in a college of education first year class teaching plane shapes such as triangles (including congruent and similar triangles), rectangles, parallelograms, rhombi, squares and their properties. At the time of the data collection, there was an average of 35 pre-service teachers in a class and each geometry lesson lasted for an average of one hour. The classroom observation protocol that was designed integrated elements of the van Hiele Levels. The researchers with particular interest observed the structure of lessons, introductions, presentations, evaluations and classroom management of lessons with a particular focus on the measures that surround the van Hiele Levels. During each tutors lesson, keen observations were made as against the various descriptions of criteria surrounding the van Hiele theory on the observation checklist developed. Thus, for each tutor's lesson, clear indications of the strength of the lesson were made in line with the van Hiele Levels. That is, whether the lesson was weak, moderate or strong in developing geometric thinking at van Hiele Level 1, 2, 3 and 4. In cases where there was the need for additional comments, the researchers provided that in a column given. The researchers also deeply observed and noted the transition from various forms of direct instruction as a tutor moved through the teaching phases towards the pre-service teachers' independence from the tutor.

\section{Analysis of Data}

In analyzing the data, it was important to deeply understand the nature of the van Hiele theory. After a profound study of the van Hiele framework as well as van Hiele-based research on the teaching phases and thinking levels, the researchers formulated an operational characterization of the theory in plane shapes teaching and used it to analyse data collected in the Ghanaian college of education classroom.

In order to explore more rigorously how colleges of education mathematics tutors facilitate the learning of geometry, the study adopted qualitative research methods. Data analysis thus, involved contextualization; which involves the interpretation of research findings with reference to data obtained from interviews and observations (Mertler \& Charles, 2005). In this study, the researchers recounted all events that originated from the study by describing and interpreting the outcomes. Hittleman and Simon $(2002$, p.38) state that the basic qualitative research purposes are to "...describe, interpret, verify and evaluate" and further elaborate by saying that "... in interpretive analysis, the researcher explains or creates generalizations". Patterns that emerged from the classroom observation in this study were described in connection with the elements that characterize the van Hiele theory so that one can make meaning from the data.

\section{RESULTS}

The themes discussed in this section were derived from the classroom observations. They also represent some of the characteristic teaching elements of the van Hiele Levels. The researchers report on the observations according to the following themes:

- Observations regarding displaying of shapes.

- Observations regarding the use of language to describe shapes.

- Observations regarding providing hands-on activities for pre-service teachers.

- Observations regarding guiding pre-service teachers to establish the properties of a shape.

- Observations regarding guiding pre-service teachers to analyze properties of geometric shapes and interrelationship between different types of shapes.

- Observations regarding the development and usage of accurate terminology.

- Observations regarding guiding pre-service teachers to create, compare and contrast different proofs.

\section{Observations regarding Displaying of Shapes}

Among the eleven colleges of education mathematics tutors observed, six of them had a variety of different geometric shapes to show to their classes as should be done in line with van Hiele Level 1. These were five male and a female mathematics tutor. These shapes were triangles and parallelograms (squares, rectangles and rhombi). It was also noted that apart from these six tutors, none of the other tutors provided examples of the properties of 
shapes. During the lessons, some of the tutors emphasized that the pre-service teachers had been taught such shapes as triangles and parallelograms at their previous Levels of education (junior high school and senior high school) thus, they were already familiar with them and therefore there was no need to display such shapes to them again. This strategy, from the researchers' observation, was weak in developing geometric thinking at van Hiele Level 1; the strategy did not help the pre-service teachers to visualize the shapes even though they were familiar with them.

Although pre-service teachers had been taught such shapes during their mathematics lessons at the junior high school and senior high school Levels, it was observed that during the six tutors' lessons, pre-service teachers were stimulated and motivated through a visualization approach. Pre-service teachers were able to visualize shapes to considerably develop geometric thinking. However, majority of the tutors provided some routine problems on shapes and asked the pre-service tutors to solve using the area and perimeter formula rather than referring to the properties in general. This is a strong strategy and it is consistent with van Hiele Level 1, as pre-service teachers know the perimeter and area formulae from their previous Levels of education.

\section{Observations regarding the Use of Language to Describe Shapes}

In line with van Hiele Level 1, observations were made to determine whether the tutors used informal as well as formal language to describe shapes and whether the tutors encouraged pre-service teachers to describe in their own words the properties of a typical shape. It was observed that the tutors frequently guided pre-service teachers to use both informal and formal language to describe shapes. The following are some examples:

Tutor A:

The tutor asked pre-service teachers to describe a scalene triangle in their own words. One of the pre-service teachers answered, "in a scalene triangle all the parts have different measure".

Tutor E:

The tutor asked pre-service teachers to describe a rectangle. One pre-service teacher answered

"a rectangle is a figure with opposite sides equal and also parallel"

Apart from these examples, it was also observed that the tutors themselves also used informal language to describe shapes. These examples show that tutors encourage pre-service teachers to describe concepts in their own words using informal language which is regarded as a strong strategy in developing Level 1 geometric thought within the van Hiele theory (van Hiele, 1986; Yazdani, 2007).

\section{Observations regarding Providing Hands-on Activities for Pre-service Teachers}

In line with van Hiele Level 2, observations were carried out to determine whether tutors provided hands-on activities to pre-service teachers requiring them to focus on the properties of shapes and to use vocabulary appropriately. Observations showed that only three of the tutors provided hands-on activities to their pre-service teachers. The activities designed for the pre-service teachers included the use of mathematical instruments and paper cut-outs in constructing, folding, reflecting, rotating and measuring plane shapes such as triangles, squares, rectangles and rhombi. Again, these tutors asked pre-service teachers to construct shapes according to their properties. These were described as strong strategies. However, majority (eight) of the tutors taught concepts of shapes theoretically using the chalk or marker boards and teaching was greatly dominated by the tutors. This was a weak strategy in developing van Hiele Levels 2 and 3 thinking. Once again, from the classroom observations, the assumptions of the tutors were that the pre-service teachers had been taught concepts of shapes at their previous Levels of education (junior high school and senior high school) thus, there was no need for any hands-on activities.

\section{Observations regarding Guiding Pre-service Teachers to Establish the Properties of a Shape}

Teaching learners how to empirically establish the properties of a typical shape is regarded as Level 2 geometric thought within the van Hiele theory. It is easier and logical to establish properties of a typical shape by first undertaking hands-on activities on those shapes (van Hiele, 1986; Vojkuvkova, 2012). Since most of the tutors did not provide any hands-on activities on geometrical shapes to pre-service teachers which required them to focus on the properties of the shapes, it was observed that those tutors could not logically guide pre-service teachers to empirically establish the properties of a typical shape. However, it was observed that the three tutors who provided some well-designed hands-on activities for their learners were much able to guide them in establishing properties of plane shapes. 


\title{
Observations regarding Guiding Pre-service Teachers to Analyze Properties of Geometric Shapes and Interrelationship between Different Types of Shapes
}

Van Hiele (1999) posited that at van Hiele Level 3:

\begin{abstract}
Students use properties that they already know to formulate definitions, for example, for squares, rectangles, and equilateral triangles, and use them to justify relationships, such as explaining why all squares are rectangles or why the sum of the angle measures of the angles of any triangle must be 180 (p. 311).
\end{abstract}

In order to effectively help learners analyze properties of geometric shapes and see the interrelationship between different types of shapes, appropriate activities should be designed for them (Abu \& Abidin, 2013; Kutluca, 2013; van Hiele, 1999). It was expected that tutors provide hands-on activities to pre-service teachers, however, most of them did not. Therefore, guiding pre-service teachers to analyze properties of geometric shapes and interrelationship between different types of shapes was difficult for the tutors and most of them did not achieve this.

\section{Observations regarding the Development and Usage of Accurate Terminology}

Observations were made to determine whether tutors ensured that the accurate and appropriate geometric terminology is developed and used. Classroom observations revealed that most of the tutors ensured the development and usage of accurate geometric terminology. Below are examples by some tutors

Tutor A:

The tutor drew an isosceles triangle on the board and asked pre-service teachers to name and describe it. One pre-service teacher answered, "it's a triangle with two equal parts and two equal angles". The tutor asked the pre-service teacher to use the appropriate terminology to describe the triangle well. Another pre-service teacher answered, "it's an isosceles triangle; it has two opposite sides and angles equal". The tutor then emphasized that "it's an isosceles triangle and the equal angles are called base angles. In a triangle, equal angles face equal sides".

Tutor C:

The tutor asked pre-service teachers to define perpendicular lines. One pre-service teacher answered, "they are lines that form an angle of $90^{\circ}$. The tutor then emphasized that "yes, they are lines that meet at $90^{\circ}$ or right angles".

These techniques were described as strong strategies and are consistent with the van Hiele theory and operate at van Hiele Levels 2 and 3.

\section{Observations regarding Guiding Pre-service Teachers to Create, Compare and Contrast Different Proofs}

At van Hiele Level 4 learners should be able to construct proofs, understand the role of axioms and definitions, and also know the meaning of necessary and sufficient conditions (Yazdani, 2007). Mathematics course outline for college of education pre-service teachers indicate that they are to be taught "congruent and similar triangles" where they are to use criteria or postulates to prove whether triangles are congruent or not. Also, under the topic "circle theorems", the pre-service teachers are to do some simple proofs. It was observed that only two tutors carried out some deductive geometric proofs with pre-service teachers. However, the proofs were not presented in a rigorous manner and also most of the proof exercises given to the pre-service teachers were not challenging to invoke high level thinking as in van Hiele Level 4. This strategy was described as moderate. Apart from these tutors the others only discussed the various types of triangles and their properties on the topic "congruent and similar triangles". No deductive geometric proofs were carried out to facilitate understanding of van Hiele Level 4 . This was on the other hand described as a weak strategy in developing van Hiele Level 4 geometric thinking.

\section{DISCUSSION AND CONCLUSION}

Whereas the van Hiele theory is said to have tremendous pedagogical benefits in geometry education, research is still limited about its use and effect on the spatial ability and geometric knowledge for teaching among preservice teachers in Ghana. The purpose of the study was to use the van Hiele theory in investigating teaching strategies used by the college of education geometry tutors in Ghana and thus, provide a rich and in-depth 
description of the geometry instructional practices at the college of education level in Ghana. In this study, each college tutor's lesson (on two-dimensional geometry) was observed twice with particular emphasis on the measures that surround the van Hiele Levels.

Contextual analysis of the data from classroom observation revealed that the selected college of education mathematics tutors exhibit a good conceptual understanding of geometry in facilitating the teaching and learning of geometry that is consistent with van Hiele Levels 1 and 2. For instance, tutors displayed geometric shapes to preservice teachers, tutors encouraged pre-service teachers to describe concepts in their own words using informal language and tutors also ensured that the accurate and appropriate geometric terminology is developed and used. These results confirm the findings (Ding \& Jones, 2007; Muyeghu, 2008) that teachers provide opportunities for learners to develop geometric thinking skills needed to operate at basic van Hiele Levels (i.e. levels 1 and 2). As Armah et al. (2017) acknowledged, it is anticipated that involving pre-service teachers in more effective geometry lessons could make them feel competent and to have absolute control in their future teaching practices at the basic school.

Key to this study is the finding that majority (eight) of the tutors taught most geometric concepts theoretically using only textbooks, chalk and marker boards with the lessons greatly dominated by the tutors themselves as reported in literature (Atebe, 2008; De Villiers 2012; Khalid \& Azeem, 2012; Yegambaram \& Naidoo, 2009). Consequently, these tutors did not choose materials and tasks which targeted the key concepts and procedures under consideration. Teaching was therefore not inspiring, enthusiastic and challenging. The results also confirm the finding (van Putten, 2008) that many pre-service teachers are taught geometry with route learning methods, using textbooks to present geometric concepts. This according to Armah et al. (2017) may have resulted in the low geometric thinking levels of most pre-service teachers as currently reported in colleges of education in Ghana. However, the study found that three tutors did otherwise by providing some carefully designed hands-on activities for their pre-service teachers which is significant to mention at this point. The activities included using such mathematical instruments as pair of compasses, protractor, pencils, measuring ruler and paper cut-outs in constructing, folding, reflecting, rotating and measuring plane shapes such as triangles, squares, rectangles and rhombi. Even though the activities involved short tasks, from keen observations these activities gradually revealed to the pre-service teachers the structured characteristic of the geometric shapes under study. To a large extent, these activities succeeded in eliciting specific responses from the pre-service teachers as they observed things about the angles, sides, and diagonals of the plane shapes.

As van Hiele (1986) reiterated, carefully designed hands-on activities are imperative for guiding students to empirically establish the properties of a shape. It was therefore not surprising that most tutors could not guide their pre-service teachers to establish properties of plane shapes as these tutors failed to assign some hands-on activities to pre-service teachers. Furthermore, to analyze properties of geometric shapes and interrelationship between different types of shapes, hands-on activities are a prerequisite (Abu \& Abidin, 2013; Kutluca, 2013). Van Hiele (1999) also explained that at van Hiele Level 3 students use properties of shapes that they already know to formulate definitions and justify relationships thus, understanding the interrelationship between different types of shapes such as squares being referred to as rectangles. Therefore, the finding that most tutors did not succeed in guiding pre-service teachers to effectively analyze properties of geometric shapes and see the interrelationship between different types of shapes was also not surprising. These findings may provide profound explanations to why studies (Armah et al., 2017; Baffoe \& Mereku, 2010) found that class inclusion (which refers to seeing the interrelationship between different types of shapes) was solely lacking among learners.

A major characteristic of learners operating at van Hiele Level 4 of geometric thinking is the ability to construct proofs, understand the role of axioms and definitions, and also know the meaning of necessary and sufficient conditions. The study found that only two tutors taught some deductive geometric proofs to pre-service teachers. However, this was done in an ineffective manner with less stimulating proof exercises been administered to preservice teachers. In a way, this did not encourage higher level thinking. Considering the level of learners involved in this study this was a disturbing phenomenon as pre-service teachers are being trained to take charge of pedagogical activities at the basic schools and thus required to exhibit geometrical thinking levels higher than their expected audience.

Based on the findings the researchers concludes that the selected college of education mathematics tutors exhibit a good conceptual understanding of geometry in facilitating the teaching and learning of geometry that is consistent with van Hiele Levels 1 and 2. However, much of the geometry teaching and learning strategies of the mathematics tutors are not structured in a way that support the development of geometric thinking as described in van Hiele Levels 3 and 4 .

In the field of mathematics teacher training and development, presenting to pre-service/prospective teachers how to go about pedagogical activities and preparing teaching and learning materials may not be anything new. However, the design of lessons with geometrically-rich tasks by teachers is currently limited in the mathematics teacher education and teaching practices particularly in Ghana. This may be a contributing factor to the abysmally 
low geometrical competencies of most Ghanaian pre-service teachers as reported in the literature (Armah et al, 2017; Gogoe, 2009). The findings in this study, therefore, support the advocacy in literature (Alex \& Mammen, 2016; Howse \& Howse, 2015; Ma, Lee, Lin, \& Wu, 2015; Noh \& Abdullah, 2016; Suwito, Yuwono, Parta \& Irawati, 2017; Tieng \& Eu, 2014) for the use of the van Hiele framework by teachers in the construction and delivery of lessons.

\section{RECOMMENDATIONS}

It is therefore recommended that teacher education institutions should integrate the van Hiele theory in the teaching of geometry concept; college of education mathematics tutors should design appropriate hands-on activities for pre-service teachers to explore properties of geometric shapes. College tutors should also guide preservice teachers in effectively exploring the interrelationship between shapes. Moreover, deductive geometric proofs should be taught in colleges of education and should be done in a thorough manner involving more challenging and thought-provoking exercises to enable pre-service teachers to operate at higher van Hiele level of geometric conceptualization. The integration of van Hiele model in teaching at teacher training institutions would not only improve upon pre-service teachers geometric thinking levels as reported in Erdogan and Durmus (2009) but also help build their competencies and craft knowledge to enable them plan geometrically-rich lessons for instructions at the basic school level later when they finish their teacher training programmes.

This study was limited to using the van Hiele theory in investigating teaching of plane shapes. Hence, it is important to indicate that these conclusions are based purely on the indicators of the van Hiele theory. It is also worth bearing in mind that although the results of the classroom observations provided information on geometry teaching strategies in the participating colleges, the observed lessons can only be partial representations of the whole process of instruction in these colleges. The findings concerning teaching strategies presented in this study are thus, tentative. Further studies could investigate teaching of other areas of geometry such as three-dimensional shapes, circles and coordinate geometry using the van Hiele theory. Also, as the present study involved only small number of college tutors in the geometry classroom with only two lessons observed, a study that would explore the geometry practices of more college tutors is very imperative to give a more general picture of college tutors' geometry teaching strategies in Ghana.

\section{REFERENCES}

Abu, M. S. \& Abidin, Z. Z. (2013). Improving the Levels of Geometric Thinking of Secondary School Students using Geometry Learning Video based on van Hiele Theory. International Journal of Evaluation and Research in Education (IJERE), 2(1), 16-22. https:// doi.org/10.11591/ijere.v2i2.1935

Al-ebous, T. (2016). Effect of the van Hiele Model in Geometric Concepts Acquisition: The Attitudes towards Geometry and Learning Transfer Effect of the First Three Grades Students in Jordan. International Education Studies, 9(4), 87-98. https:/ / doi.org/10.5539/ies.v9n4p87

Alex, J. K., \& Mammen, K. J. (2012). A Survey of South African Grade 10 Learners' Geometric Thinking Levels in Terms of the van Hiele Theory. Anthropologist, 14(2), 123-129. https:/ / doi.org/10.1080/09720073.2012.11891229

Alex, J. K., \& Mammen, K. J. (2016). Lessons Learnt from Employing van Hiele Theory Based Instruction in Senior Secondary School Geometry Classrooms. Eurasia Journal of Mathematics, Science E Technology Education, 12(8), 2223-2236. https:// doi.org/10.12973/eurasia.2016.1228a

Ampiah, J. G. (2010). Quality Basic Education in Ghana: Prescription, Praxis and Problems. Paper Delivered at the Experience Sharing Seminar. Erata Hotel Accra: Ghana.

Anamuah-Mensah, J., \& Mereku, D. K. (2005). Ghanaian Junior Secondary School two students abysmal Mathematics Achievement in TIMSS 2003: A consequence of the Basic school Mathematics. Mathematics Connection, 5(1), 1-11.

Anamuah-Mensah, J., Mereku, D. K., \& Asabere-Ameyaw, A. (2008). Ghanaian Junior Secondary School Students' Achievement in Mathematics and Science: Results from Ghana's participation in the 2007 Trends in International Mathematics and Science Study. Accra: Ministry of Education Youth and Sports.

Armah, R. B., Cofie, P. O., \& Okpoti, C. A. (2017). The Geometric Thinking Levels of Pre-service Teachers in Ghana. Higher Education Research, 2(3), 98-106.

Atebe, H. U. (2008). Students' van Hiele Levels of Geometric Thought and Conception in Plane Geometry: A Collective Case Study of Nigeria and South Africa. (Unpublished PhD. Thesis). Rhodes University, South Africa.

Baffoe, E., \& Mereku, D. K. (2010). The Van Hiele Levels of understanding of students entering Senior High School in Ghana. African Journal of Educational Studies in Mathematics and Science, 8(1), 51-61. 
Christou, C., Jones, K., Pitta, D., Pittalis, M., Mousoulides, N., \& Boytchev, P. (2007). Developing Student Spatial Ability with 3-Dimensional Applications. Retrieved on July 30, 2014 from http:/ / www.elica.net/download/papers/devstudspatabil3d.pdf

De Villiers, M. (2012). Some Reflections on the van Hiele Theory. Retrieved on April 8, 2014 from http:/ / frink.machighway.com/ dynamicm/vanhiele-reflection.pdf

Ding, L., \& Jones, K. (2007). Using the van Hiele theory to analyze the teaching of geometrical proof at grade 8 in Shanghai, China. European Society for Research in Mathematics Education, 612-621.

Erdogan, T., \& Durmus, S. (2009). The effect of the instruction based on van Hiele model on the geometrical thinking Levels of preservice elementary school teachers. Procedia Social and Behavioral Sciences, 1, 154-159. https:// doi.org/10.1016/j.sbspro.2009.01.029

Furner, J. M., \& Marinas, C. A. (2011). Geoboards to Geogebra: moving from the concrete to the abstract in geometry. Retrieved on October, 24, 2018 from http:/ / archives.math.utk.edu/ICTCM/VOL23/S088/ paper.pdf

Gogoe, M. (2009). Ghanaian preservice teachers' Geometric knowledge for teaching. (Unpublished master's thesis). Department of Mathematics Education, University of Education, Winneba, Ghana.

Güven, B., \& Kosa, T. (2008). The effect of dynamic geometry software on student Mathematics teachers' spatial visualization skills. The Turkish Online Journal of Educational Technology, 7(11), 100-107.

Halat, E. (2008). In-Service Middle and High School Mathematics Teachers: Geometric Reasoning Stages and Gender. The Mathematics Educator, 18(1), 8-14.

Hittleman, D. R., \& Simon, A. J. (2002). Interpreting educational research (3rd Ed.). Upper Saddle River, New Jersey: Merrill Prentice Hall.

Howse, T. D., \& Howse, M. E. (2015). Linking the Van Hiele Theory to Instruction. Teaching children mathematics, 21(5), 305-313.

Institute of Education (2005). Three- year diploma in basic education Mathematics syllabus. Cape Coast: University A.

Jones, K. (2002). Issues in the Teaching and Learning of Geometry. In: Linda Haggarty (Ed), Aspects of Teaching Secondary Mathematics: perspectives on practice (pp.121-139). London: Routledge Falmer. https://doi.org/10.1002/t1.62

Khalid, A., \& Azeem, M. (2012). Constructivist Vs Traditional: Effective Instructional Approach in Teacher Education. International Journal of Humanities and Social Science, 2(5), 170-177.

Kilpatrick, J., \& Findell, B. (2001). Adding it up: Helping children learn mathematics. Washington, DC: National Academy Press.

Kutluca, T. (2013). The effect of geometry instruction with dynamic geometry software; GeoGebra on Van Hiele geometry understanding levels of students. Educational Research and Reviews, 8(17), 1509-1518.

Ma, H. L., Lee, D. C., Lin, S. H., \& Wu, D. B. (2015). A Study of Van Hiele of Geometric Thinking among 1st through $6^{\text {th }}$ Graders. Eurasia Journal of Mathematics, Science $\mathcal{E}$ Technology Education, 11(5), 1181-1196.

Mason, M. (1998). The van Hiele Levels of geometric understanding. In L. McDougal (Ed.). The professional handbook for teachers: Geometry (pp. 4-8). Boston: McDougal-Littell/Houghton-Mifflin.

Mertler, C. A., \& Charles, C.M. (5th Ed.) (2005). Introduction to educational research. New York: Pearson Education, Inc.

Ministry of Education, Science and Sports (MOESS) (2007). Mathematics Syllabus for Primary School. Accra: Ministry of Education, Science and Sports. GES: CRDD.

Mostafa, M., Javad, L. M., \& Reza, O. H. (2017). The Effect of Van Hiele Theory-Based Teaching Educational Package on Achievement Goal Orientation of Student Teachers. Review of European Studies, 9(1), 93-105. https:// doi.org/10.5539/res.v9n1p93

Muyeghu, A. (2008). The use of the van Hiele theory in Investigating Teaching Strategies used by Grade 10 Geometry teachers in Namibia. (Unpublished Master's Thesis). Rhodes University, Grahamstown, RSA.

Noh, F. N. B. M., \& Abdullah, A. H. (2016). Primary School Students Level of Geometric Thinking. Retrieved on July 14, 2018 from https://www.researchgate.net/publication/308950262_PRIMARY_SCHOOL_ STUDENTS_LEVEL_OF_GEOMETRIC_THINKING

Pegg, J. (1995). Learning and teaching geometry. In L. Grimison \& J. Pegg (Eds.), Teaching secondary school mathematics: Theory into practice (pp. 87-103). London: Harcourt Brace.

Rizki, H. T. N., Frentika, D., \& Wijaya, A (2018). Exploring students' adaptive reasoning skills and van Hiele levels of geometric thinking: a case study in geometry. https:/ / doi.org/10.1088/1742-6596/983/1/012148 
Schwartz, J. E. (2008). Elementary Mathematics Pedagogical Content Knowledge: Powerful Ideas for Teachers. Retrieved on March 2, 2014 from http://www.education.com/reference/article/why-people-have-difficultygeometry/

Shulman, L. S. (1987). Knowledge and teaching: Foundations of the new reform. Harvard Educational Review, 57(1), 1-22. https:/ / doi.org/10.17763/haer.57.1.j463w79r56455411

Stigler, J. W., \& Hiebert, J. (1999). The teaching gap: Best ideas from the world's teachers for improving education in the classroom. New York: The Free Press.

Suwito, A., Yuwono I, Parta, I. N., \& Irawati, S. (2017). Geometry High School Students Thinking Ability based on level van Hiele. International Conference on Mathematics: Education, Theory and Application, Indonesia.

Thanh, N. C., \& Thanh, T. T. L. (2015). The Interconnection Between Interpretivist Paradigm and Qualitative Methods in Education. American Journal of Educational Science, 1(2), 24-27.

Tieng, P. G., \& Eu, L. K. (2014). Improving Students' Van Hiele Level of Geometric Thinking using Geometer's Sketchpad. The Malaysian Online Journal of Educational Technology, 2(3), 20-31.

Van Hiele, P. M. (1986). Structure and insight: A theory of Mathematics education. Orlando: Academic Press.

Van Hiele, P. M. (1999). Developing Geometric Thinking through Activities that Begin with Play. Teaching Children Mathematics, 6, 310-316.

van Putten S. (2008). Level of thought in geometry of pre-service mathematics educators according to the Van Hiele model. (Unpublished master's thesis). University of Pretoria, South Africa.

Vojkuvkova, I. (2012). The van Hiele Model of Geometric Thinking. WDS'12 Proceedings of Contributed Papers, 1, 7275.

Willis, J. W. (2007). Foundations of qualitative research: interpretive and critical approaches. London: Sage. https:/ / doi.org/10.4135/9781452230108

Yanow, D., \& Schwartz-Shea, P. (2011). Interpretive Approaches to Research Design: Concepts and Processes. Netherlands: Routledge.

Yazdani, M. A. (2007). Correlation between Students' level of Understanding Geometry According to the van Hieles' Model and Students' Achievement in Plane Geometry. Journal of mathematical Sciences \& Mathematics Education, 2(1), 40-45.

Yegambaram, P., \& Naidoo, R. (2009). Better learning of geometry with computer. Retrieved on January 16, 2014 from http://atcm.mathandtech.org/EP2009/papers_full/2812009_17080.pdf 


\section{APPENDIX}

\section{OBSERVATION SCHEDULE FOR TUTORS BASED ON THE VAN HIELE THEORY}

Subject:.

Date....

Lesson starts:

Lesson ends:

Teacher observed

Observer:

Level: 100

Topic:

Objective(s):

Activities

Level Weak Moderate Strong Comments

Tutor displays a variety of different readymade geometric shapes to the class.

Tutor asks learners to list examples of shapes in the outside world.

Tutor uses informal language to describe shapes.

1

Tutor asks learners to construct shapes according to their appearance.

Tutor asks learners to solve routine problems by operating on the shapes rather than referring to the properties in general.

\begin{tabular}{ll}
\hline Activities & Level Weak Moderate Strong Comments \\
\hline Tutor introduces a typical topic on properties of shapes. & 2 \\
\hline Tutor asks learners to list properties of shapes. & 2 \\
\hline $\begin{array}{l}\text { Tutor asks learners to construct shapes according to their } \\
\text { properties. }\end{array}$ & 2 \\
$\begin{array}{l}\text { Tutor teaches learners how to solve a certain problem by using } \\
\text { known properties of shapes. }\end{array}$ & 2 \\
$\begin{array}{l}\text { Tutor provides hands-on activities to learners which require them } \\
\text { to focus on the properties of the shapes. }\end{array}$ & 2
\end{tabular}

\begin{tabular}{|c|c|}
\hline Activities & Level Weak Moderate Strong Comments \\
\hline $\begin{array}{l}\text { Tutor asks learners to describe what they have learned about the } \\
\text { topic using their own language }\end{array}$ & 3 \\
\hline $\begin{array}{l}\text { Tutor guides learners to analyze properties of geometric shapes } \\
\text { and to understand the interrelationship between different types of } \\
\text { shapes }\end{array}$ & 3 \\
\hline $\begin{array}{l}\text { Tutor guides learners to make simple inferences e.g. in a } \\
\text { quadrilateral, opposite sides being parallel necessitates opposite } \\
\text { angles being equal. }\end{array}$ & 3 \\
\hline $\begin{array}{l}\text { Tutor ensures that the accurate and appropriate terminology is } \\
\text { developed and used }\end{array}$ & 3 \\
\hline $\begin{array}{l}\text { Tutor guides learners in doing problem solving, including tasks in } \\
\text { which properties of shapes are important components }\end{array}$ & 3 \\
\hline Activities & Level Weak Moderate Strong Comments \\
\hline $\begin{array}{l}\text { Tutor designs tasks that provide the learners with problems that } \\
\text { are open-ended and have multi-path solutions. }\end{array}$ & 4 \\
\hline $\begin{array}{l}\text { Tutor guides learners to create, compare, and contrast different } \\
\text { proofs. }\end{array}$ & 4 \\
\hline $\begin{array}{l}\text { Tutor guides learners to supply reasons for statements in formal } \\
\text { proofs }\end{array}$ & 4 \\
\hline
\end{tabular}

\section{http://www.ejmste.com}

